\title{
Article \\ Comparison of Two Schizophyllum commune Strains in Production of Acetylcholinesterase Inhibitors and Antioxidants from Submerged Cultivation
}

\author{
Jovana Mišković ${ }^{1,+}$, Maja Karaman ${ }^{1, *,+}$, Milena Rašeta ${ }^{2}$, Nenad Krsmanović ${ }^{1}$, Sanja Berežni ${ }^{2}$, \\ Dragica Jakovljević ${ }^{3}$, Federica Piattoni ${ }^{4}$, Alessandra Zambonelli ${ }^{5} \mathbb{D}$, Maria Letizia Gargano ${ }^{6}$ and \\ Giuseppe Venturella ${ }^{7}$ (D)
}

\section{check for} updates

Citation: Mišković, J.; Karaman, M.; Rašeta, M.; Krsmanović, N.; Berežni, S.; Jakovljević, D.; Piattoni, F.; Zambonelli, A.; Gargano, M.L.; Venturella, G. Comparison of Two Schizophyllum commune Strains in Production of Acetylcholinesterase Inhibitors and Antioxidants from Submerged Cultivation. J. Fungi 2021, 7, 115. https://doi.org/10.3390/ jof7020115

Academic Editor: Jasmina Glamočlija Received: 13 December 2020

Accepted: 20 January 2021

Published: 4 February 2021

Publisher's Note: MDPI stays neutral with regard to jurisdictional claims in published maps and institutional affiliations.

Copyright: (c) 2021 by the authors Licensee MDPI, Basel, Switzerland. This article is an open access article distributed under the terms and conditions of the Creative Commons Attribution (CC BY) license (https:/ / creativecommons.org/licenses/by/ $4.0 /)$.
1 Department of Biology and Ecology, Faculty of Sciences, University of Novi Sad, TrgDositejaObradovića 2, 21000 Novi Sad, Serbia; jovana.maric@dbe.uns.ac.rs (J.M.); nenad.krsmanovic@dbe.uns.ac.rs (N.K.)

2 Department of Chemistry, Biochemistry and Environmental Protection, Faculty of Sciences, University of Novi Sad, Trg Dositeja Obradovića 3, 21000 Novi Sad, Serbia; milena.raseta@dh.uns.ac.rs (M.R.); sanja.beric@dh.uns.ac.rs (S.B.)

3 Institute of Chemistry, Technology and Metallurgy, University of Belgrade, Njegoševa 12, 11000 Belgrade, Serbia; djakovlj@chem.bg.ac.rs

4 Laboratory of Genetics \& Genomics of Marine Resources and Environment (GenoDream), Department Biological, Geological \& Environmental Sciences (BiGeA), University of Bologna, Via S. Alberto 163, 48123 Ravenna, Italy; federica.piattoni@unibo.it

5 Dipartimento di Scienze e Tecnologie Agroalimentari, University of Bologna, Via Fanin 46, 40127 Bologna, Italy; alessandr.zambonelli@unibo.it

6 Department of Agricultural and Environmental Science, University of Bari "Aldo Moro", Via Amendola 165/A, I-70126 Bari, Italy; marialetizia.gargano@uniba.it

7 Department of Agricultural, Food and Forest Sciences, University of Palermo, Via delle Scienze, Bldg. 4, 90128 Palermo, Italy; giuseppe.venturella@unipa.it

* Correspondence: maja.karaman@dbe.uns.ac.rs

$\dagger$ These two authors equally contributed to the performed study.

Abstract: In recent years, fungi have been recognized as producers of acetylcholinesterase (AChE) inhibitors, agents important for the prevention of Alzheimer's disease (AD). This study aimed to examine the AChE inhibitory, the antioxidative and antibacterial activity of two different Schizophyllum commune strains that originated from Serbia (SRB) and Italy (IT). Submerged cultivation of grown mycelia (M) and fermentation broth (F) of ethanol (EtOH) and polysaccharide (PSH) extracts lasted for 7, 14, 21 and 28 days. For AChE activity Ellman method was performed, while for antioxidative activity, sevendifferent assays were conducted: DPPH, ABTS, FRAP, SOA, OH, NO together with total phenolic content. Antimicrobial screen, LC-MS/MS technique and FTIR measurements were performed. Different isolates exhibited different AChE activity, with PSH being the strongest (SRB, M, 28 days $\mathrm{IC}_{90} 79.73 \pm 26.34 \mu \mathrm{g} / \mathrm{mL}$ ), while in EtOH extracts, IT stood out $\left(\mathrm{F}, 14\right.$ days, $\mathrm{IC}_{50}$ $0.8 \pm 0.6 \mu \mathrm{g} / \mathrm{mL}$ ). PSH extracts (7 days) exhibit significant antioxidative activity (AO), opposite to EtOH extracts where 14 and 21days periods stood out. Only tw extracts showed antibacterial activity. Following LC-MS/MS analysis $p$-hydroxybenzoic and gallic acids were the most abundant phenolics. PSH extracts demonstrated remarkable results, making this study debut and introducing $S$. commune as a valuable resource of AChE inhibitors.

Keywords: Schizophyllum commune; submerged cultivation; acetylcholinesterase inhibition; antioxidant

\section{Introduction}

Reactive oxygen species (ROS) represent the most potent free radicals since they can have a destructive effect on various cells and cause oxidative stress [1,2]. The imbalance between the production and quenching of free radicals may lead to a wide range of diseases, including neurodegenerative disorders such as Alzheimer's (AD) [3]. Even though the 
exact cause of $\mathrm{AD}$ remains a question of debate, various studies suggest that oxidative stress plays a key role in an early response [2-5]. Furthermore, due to a lack of treatment to stop or reverse its progression, acetylcholinesterase inhibitors (AChI) have become an attractive research topic. AChI medications can help with memory symptoms and other cognitive changes by increasing the level of acetylcholine in the brain [6]. Hence, a wide range of organisms have been studied in order to find a biologically active compound that would be a successful AChI [7] and today, the only natural approved agents are alkaloids, such as galantamine and huperzine A [8]. Nevertheless, problems with bioavailability and numerous side effects pointed out that there is aneed for other AChI [7-9].

In recent years, mushrooms have been recognized as producers of non-alkaloid agents that inhibit acetylcholinesterase enzyme (AChE) $[10,11]$ as well as the organisms which possess naturally occurring antioxidants [12]. Many structurally different polysaccharides with high antitumor activity and no side effects have been isolated from fungi [13], and it has been observed that they have the ability to improve memory and learning [14,15]. In addition, secondary metabolites, mostly phenolics, are considered to be responsible for antioxidant activity (AO) $[10,16]$. Submerged cultivation represents a controlled biotechnological process for providing valuable mycelial biomass and extracellular medium, which contain different organic compounds and may show different properties. Moreover, it can provide a faster route for antioxidant and exopolysaccharide production in basidiomycetes [17].

Schizophyllum commune (phylum Basidiomycota, order Agaricales, family Schizophyllaceae) is a widely distributed wood-decaying basidiomycete-that is present on all continents except Antarctica, but it is more common to be found in warmer regions with high humidity [18]. Thanks to the production of a neutral extracellular polysaccharide schizophyllan (Sonifilan, SPG), a $\beta-1,3$ glucan with $\beta-1,6$ branching and molecular weight of $450 \mathrm{kDa}$, that has shown significant antitumor, anticancer, immunomodulatory and anti-inflammatory effects $[12,19,20]$, other benefits of this mushroom are being investigated [15]. Considering that environmental conditions in different geographical regions influence, to a great extent on the bioactive properties, the purpose of this study was to examine and compare AChE inhibitory and antioxidative activity, in vitro, of ethanol and polysaccharide extracts of two different strains of S. commune originated from Serbia (SRB) and Italy (IT). Both isolates were cultivated in submerged conditions in order to examine and compare the activity of mycelium biomass $(\mathrm{M})$ and fermentation broth $(\mathrm{F})$.

\section{Materials and Methods}

\subsection{Biological Material}

Two dikaryon strains of the wild-growing S. commune Fries 1815. (Ph. Basidiomycota, Cl. Agaricomycetes, O. Auriculariales, Fam. Schizopyllaceae) were collected near Bologna, Italy, in 2016 and in Zmajevac (Fruška Gora mountain) in Serbia in 2012. Mushroom identification was carried out by studying the fungal morphology macroscopically (color, shape, size and hyphae) and microscopically [21]. Mycelia wereisolated from the fruiting bodies of both isolates and cultivated at $26^{\circ} \mathrm{C}$, for 10 days, on malt agar (Torlak, Serbia). Mycelia of both isolates were deposited in fungal culture collection FUNGICULT, (https: / / www.pmf.uns.ac.rs/en/research/groups/profungi/), of the ProFungi laboratory at Department of Biology and Ecology-DBE, Faculty of Natural Sciences-PMF, University of Novi Sad-UNS. The isolates were referenced under the following numbers: 0043 and 0047, respectively, for S. commune SRB and IT.

\subsection{Submerged Cultivation and Preparation of Extracts}

Mycelia of SRB and IT strain from culture collection were cultivated on malt agar (Torlak, Serbia) at $26^{\circ} \mathrm{C}$ for 12 days in a thermal incubator in the dark, each isolate in triplicate. A sterilized fermentation medium was prepared in Erlenmeyer flasks ( $500 \mathrm{~mL}$ narrow throat flasks), in which 5 plaques of pure culture mycelia, approx. $1 \mathrm{~cm}^{2}$ in size, were transferred into $100 \mathrm{~mL}$ of fermentation broth that contained $0.5 \mathrm{~g}$ peptone, $3.7 \mathrm{~g}$ glu- 
cose, $0.17 \mathrm{~g}$ maltose, $0.17 \mathrm{~g}$ fructose, $0.17 \mathrm{~g}$ xylose, $0.5 \mathrm{~g}$ yeast extract, $0.1 \mathrm{~g} \mathrm{~K}_{2} \mathrm{HPO}_{4}$, $0.05 \mathrm{~g} \mathrm{MgSO}_{4} \times 7 \mathrm{H}_{2} \mathrm{O}$ and $0.005 \mathrm{~g}$ vitamin B1. Incubation on a rotary shakerat $120 \mathrm{rpm}$, $26^{\circ} \mathrm{C}$ and in the light (IKA KS 4000i control, Werke GmbH and Co.KG, Staufen, Germany) lasted for 7, 14, 21 and 28 days. Every 7 days, three replicates of SRB and IT isolates were filtered (diaphragm vacuum pump GM-0.5, HINOTEK Group Limited, China) and lyophilized at $-80{ }^{\circ} \mathrm{C}$ under vacuum (Bio alpha, Martin Christ $\mathrm{GmbH}$, Switzerland), $\mathrm{F}$ for $72 \mathrm{~h}$ and $\mathrm{M}$ for $48 \mathrm{~h}$. Afterward, samples were grounded to a fine powder (IKA A11 basic, Germany) and kept in dark bottles at room temperature until further use. Based on the measured masses of mycelium and lyophilized filtrate, appropriate growth curves were made (Figures S1 and S2). The mass of each strain was derived from $1200 \mathrm{~mL}$ of fermentation medium (three replicates with $100 \mathrm{~mL}$ for each incubation time). Ethanol extracts $(\mathrm{EtOH}), \mathrm{M}$ and $\mathrm{F}$, were prepared by mixing $5 \mathrm{~g}$ of fungal material with $100 \mathrm{~mL}$ of 96\% ethanol-EtOH (Zorka Pharma, Serbia) and stirring at $120 \mathrm{rpm}$ at room temperature for 72 h. Afterward, extracts were evaporated (Buchi R-210, Switzerland) until the dry weight (d.w.) is reached and redissolved in $80 \% \mathrm{EtOH}$ to achieve a concentration of 10 and $20 \%(w / v)$. Polysaccharide (PSH) extracts were prepared according to Ren et al. with some modifications [22]. The modifications refer to the centrifugation speed;more precisely, instead of 14,000 rpm, 12,000 rpm was performed.

\subsection{Determination of AChE Activity}

In vitrodetermination of $\mathrm{AChE}$ inhibitory activity of $\mathrm{PSH}$ and $\mathrm{EtOH}$ extracts was done according to Ellman et al. adapted for the use in 96-well microplates [23]. As an artificial substrate, acetylcholine iodide-AChI, originating from electric eel (Sigma-Aldrich, Chemie $\mathrm{GmbH}$-Schnelldorf, Germany), was used for degradation of the AChE enzyme (SigmaAldrich, Merck Group, Germany). The reaction mixture contained $20 \mu \mathrm{L}$ of the fungal extract, $150 \mu \mathrm{L}$ of reagent A (Ellman's reagent and AChI) and $50 \mu \mathrm{L}$ of reagent B (AChE enzyme at $518 \mathrm{U} / \mathrm{mL}$ previously dissolved in phosphate buffer, $\mathrm{pH}$ 8.0), while donepezil at $1 \mathrm{mg} / \mathrm{mL}$ (Donecept, Zdravlje, Leskovac, Serbia) was used as a positive control. The absorbance was measured at $\lambda=412 \mathrm{~nm}$ on a 96-well plate reader (Multiskan Ascent, Thermo Electron Corporation, USA) in a total of 15 measurements with an interval of $1 \mathrm{~min}$. The concentration range of analyzed extracts was from $10 \%$ to $0.01 \%$. The percentage (\%) of enzyme inhibition was calculated based on the following Equation (1):

$$
\mathrm{I}_{\mathrm{AChE}}(\%)=\left(1-\mathrm{A}_{\text {sample }} / \mathrm{A}_{\text {control }}\right) \times 100 \%
$$

where $\mathrm{A}_{\text {sample }}$ and $\mathrm{A}_{\text {control }}$ stand for the absorbance of the tested and control samples, respectively. All measurements were performed in triplicate, and the results were presented as $\mathrm{IC}_{50}$ and $\mathrm{IC}_{90}$ values, with lower values corresponding to higher AChE activity of the sample. The reference inhibition time is a period of $10 \mathrm{~min}$ or $600 \mathrm{~s}$, respectively.

\subsection{Determination of Antioxidant Activity}

For the in vitro evaluation of the $\mathrm{AO}$ of $\mathrm{PSH}$ and EtOH extracts, the scavenging effect on 2,2'-diphenyl-1-picrylhydrazyl (DPPH) and 2,2'-azinobis(3-ethylbenzthiazolin)6sulfonic acid (ABTS) radicals, in addition to ferric reducing antioxidant power assay (FRAP assay) of extracts was determined. Additionally, the capability to neutralize superoxide anion (SOA, $\mathrm{O}_{2}^{-}$), hydroxyl $\left(\mathrm{OH}^{-}\right)$and nitric oxide radical ( $\mathrm{NO}^{-}$) was assessed for EtOH. Synthetic antioxidant propyl gallate (PG) was used as a positive control for RSC assays, and all assays were completed in triplicates. The results were presented as the mean values \pm standard deviations (SD).2.4.1. DPPH Assay

The DPPH free radical scavenging assay was carried out according to the previously described procedure [24]. Briefly, the reaction mixture contained $60 \mu \mathrm{L}$ of $90 \mu \mathrm{M} \mathrm{DPPH}$ reagent, $180 \mu \mathrm{L} \mathrm{MeOH}$ and $10 \mu \mathrm{L}$ of the relevant $S$. commune extract (EtOH and PSH). The mixture was kept in the dark at room temperature for $30 \mathrm{~min}$, and the absorbance was 
measured at $\lambda=515 \mathrm{~nm}$ (multiscan, Thermo Scientific, Waltham, MA, USA). The following Equation (2) was used for the calculation of radical scavenging capacity (RSC):

$$
\operatorname{RSC}_{(\mathrm{DPPH})}(\%)=\left(1-\mathrm{A}_{\text {sample }} / \mathrm{A}_{\text {control }}\right) \times 100 \%
$$

where $\mathrm{A}_{\text {sample }}$ and $\mathrm{A}_{\text {control }}$ stand for the absorbance of the tested extracts and control. After regression analysis, results were presented as $\mathrm{IC}_{50}$ values $(\mu \mathrm{g} / \mathrm{mL}$ ) (the concentration of the test substance at which $50 \%$ of the radicals is neutralized).

\subsubsection{ABTS Assay}

The ABTS test, based on spectrophotometric monitoring of the transformation of the blue-green colored cation radical $\mathrm{ABTS}^{+}$into its neutral, colorless form, was carried out according to Arnao et al. [25]. $\mathrm{ABTS}^{+}$was produced directly by reacting $7 \mathrm{mM}$ ABTS solution with $2.45 \mathrm{mM} \mathrm{K}_{2} \mathrm{~S}_{2} \mathrm{O}_{8}$, and after incubation (12-16 $\mathrm{h}$ in the dark at the room temperature) on the day of the assay, ABTS solution was diluted with $\mathrm{EtOH}$ to achieve absorbance between 0.800 and 0.900 at $\lambda=734 \mathrm{~nm}$. $10 \mu \mathrm{L}$ of fungal extract (EtOH and PSH) was added to $290 \mu \mathrm{L}$ of ABTS solution and mixed. The sample absorbance was read at $\lambda=734 \mathrm{~nm}$ after a 5 -min incubation at room temperature, while Trolox was used to calculate the standard curve. The ABTS radical scavenging activity was expressed as mg of Trolox equivalents per g dry weight (mg TE/g d.w.).

\subsubsection{FRAP Assay}

FRAP assay was done by the method of Benzie and Strain [26]. The fresh FRAP reagent consists of $10 \mathrm{mmol} / \mathrm{LTPTZ}$ solution in $40 \mathrm{mmol} / \mathrm{L} \mathrm{HCl}, 0.02 \mathrm{mmol} / \mathrm{L} \mathrm{FeCl}_{3} \times 6 \mathrm{H}_{2} \mathrm{O}$ and acetate buffer ( $\mathrm{pH}$ 3.6) in ratio 10:1:1. For the assay, $10 \mu \mathrm{L}$ of each extract was mixed with $225 \mu \mathrm{L}$ of FRAP reagent and $22.5 \mu \mathrm{L}$ of $\mathrm{dH}_{2} \mathrm{O}$. The absorbance was measured after 6 min at 593, while ascorbic acid (AA) was used to calculate the standard curve. Reducing power of analyzed fungal extracts (EtOH and PSH) was expressed mg AA equivalents per g dry weight (mg AAE/g d.w.).

\subsubsection{Superoxide Anion Radical Scavenging (SOA) Assay}

The antiradical $\mathrm{O}_{2}{ }^{-}$the activity of tested $\mathrm{EtOH}$ extracts was evaluated by a previously described method [27], based on measuring extract the ability to neutralize these radicals formed during aerobic reduction of NBT by NADH in the presence of phenazine methyl sulfate. The standard antioxidant PG was used as a positive control, and the neutralization potential of $\mathrm{RSC}_{\mathrm{O} 2-\mathrm{w}}$ as calculated according to the formula in Section 2.4.1. The results were expressed as the mean of the three $\mathrm{IC}_{50}$ values obtained $\pm \mathrm{SD}(\mu \mathrm{g} / \mathrm{mL})$.

\subsubsection{OH Assay}

RSC activity of $\mathrm{OH}^{\cdot}$ was determined by the modified method of Halliwell and Gutteridge [28]. $100 \mu \mathrm{L} \mathrm{H}_{2} \mathrm{O}_{2}, 100 \mu \mathrm{L} \mathrm{FeSO}_{4}$ and $100 \mu \mathrm{L}$ 2-deoxyribose-D-ribose were mixed with different concentration of EtOH fungal extract $(10 \mu \mathrm{L})$ and $2.7 \mathrm{~mL}$ of phosphate buffer (pH 7.4). Samples were incubated for $60 \mathrm{~min}$ at $37^{\circ} \mathrm{C}$, and $200 \mu \mathrm{L}$ of EDTA (ethylenediaminetetraacetic acid) and $2 \mathrm{~mL}$ of TBA reagent $(5.2 \mathrm{~mL}$ perchloric acid, $1.5 \mathrm{~g}$ thiobarbituric

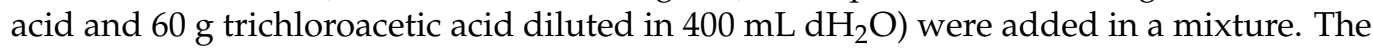
absorbance of the reaction mixture (pink complex) was noted at $\lambda=532 \mathrm{~nm}$, and results were expressed as $\mathrm{IC}_{25}$ values $\pm \mathrm{SD}(\mu \mathrm{g} / \mathrm{mL})$.

\subsubsection{NO Assay}

The concentration of nitrite ions was determined according to Green et al. [29]. The reaction mixture contained $15 \mu \mathrm{L}$ of extract, $250 \mu \mathrm{L} 10 \mathrm{mmol} / \mathrm{L}$ sodium nitroprusside and $250 \mu \mathrm{L}$ phosphate buffer ( $\mathrm{pH}$ 7.4). After incubation (90 min at room temperature and constant light), $500 \mu \mathrm{L}$ of Griess reagent (a mixture of $0.2 \%$ solution of $\mathrm{N}$-(1-naphthyl)ethylenediamine dihydrochloride and $2 \%$ solution of sulfanilamide in $4 \%$ phosphoric acid) 
was added. The absorbance was measured at $\lambda=546 \mathrm{~nm}$, and RSC was expressed as $\mathrm{IC}_{25} \pm \mathrm{SD}(\mu \mathrm{g} / \mathrm{mL})$.

\subsection{Antibacterial Activity}

In vitroantibacterial susceptibility, assays were performed using 2 Gram-positive (Staphylococcusaureus and Bacillus cereus) and Gram-negative (Escherichia coli and Pseudomonasaeruginosa) bacteria strains from American Type Culture Collection (ATCC). Antimicrobial screen included agar-well diffusion and disc-diffusion assays in the evaluation of the antibacterial activity of EtOH fungal extracts of stock concentration, 10\% $(w / v)$. Evaluation of activity was performed according to the CLSI procedure [30] and the previously described method [16]. Evaluation of minimal inhibitory concentration (MIC) and minimal bactericidal concentration (MBC) was performed by the two-fold dilution susceptibility method according to the CLSI procedure [31] and Karaman et al. [32]. All tests were carried out in triplicate.

\subsection{Determination of Total Phenolic Content}

Determination of the total phenolic content (TP) was performed by the method of Singleton et al. [33]. Extracts were examined in the concentration of 0.625 to $50 \mathrm{mg} / \mathrm{mL}$, while gallic acid (standard compound) was prepared in ten concentrations ranging from 0 to $100 \mu \mathrm{g} / \mathrm{mL} 25 \mu \mathrm{L}$ of each extract or standard solution, except in blank probe where only the solvent was used $(80 \% \mathrm{EtOH})$, was added to $125 \mu \mathrm{L}$ of $0.1 \mathrm{~mol} / \mathrm{L}$ Folin-Ciocâlteu reagent $(\mathrm{FC})$ and mixed with $100 \mu \mathrm{L}$ of sodium carbonate $(7.5 \%)$ after $10 \mathrm{~min}$. Absorbance at $\lambda=760 \mathrm{~nm}$ was read after $2 \mathrm{~h}$ incubation time. The phenolics concentration was determined by comparison with the standard calibration curve of gallic acid, and results were presented as a mean value of triplicated $\pm \mathrm{SD}$. The total phenol value was expressed as $\mathrm{mg}$ of gallic acid equivalents (GAE) per $g$ of dry weight.

\subsection{Fourier Transform Infrared Spectroscopy Analysis (FTIR)}

FTIR spectra of the EtOH and PSH spectra were recorded on a Thermo-Nicolet Model 6700 spectrophotometer (Thermo Scientific, USA) equipped with Smart Orbit (Diamond) ATR accessory and OMNIC 7.3 software. Spectra were recorded in the $400-4000 \mathrm{~cm}^{-1}$ wave number range.

\subsection{Hydrolysis}

For analysis of the monosaccharide composition of PSH extracts, paper chromatography was applied. Each lyophilized PSH extract $(2 \mathrm{mg})$ was hydrolyzed with 2 M TFA ( $2 \mathrm{~mL})$ in a sealed tube at $100{ }^{\circ} \mathrm{C}$ overnight. Samples were concentrated by evaporation under reduced pressure (below $50^{\circ} \mathrm{C}$ ) to dryness. Residual TFA was removed by two evaporation cycles with $0.5 \mathrm{~mL}$ of isopropanol, and the final residue was dissolved in $0.02 \mathrm{~mL}$ ofdistilled water and analyzed by PC on Whatman No.1 chromatography paper (descending method) in the solvent system ethyl-acetate:pyridine:water (10:4:3 v/v/v). Components were visualized with alkaline silver nitrate [34]. D-Galactose, D-glucose, D-mannose, D-xylose, and D-ribose were used as standards.

\subsection{LC-MS/MS Analysis}

The quantification of the selected phenolic compounds in PSH and EtOH extracts of S. commune isolates was carried out using the slightly modified LC-MS/MS method by Orčić et al. [35]. To obtain the high selectivity and sensitivity, the selected reactions monitoring (SRM) acquisition mode was used since only ions specific to the targeted analytes were monitored. Extracts and standards were analyzed using Agilent Technologies 1200 Series high-performance liquid chromatography coupled with Agilent Technologies 6410A Triple Quad tandem mass spectrometer with electrospray ion source and controlled by Agilent Technologies MassHunter Workstation software Data Acquisition (ver. B.03.01). Compounds were separated on Zorbax Eclipse XDB-C18 (50 $\mathrm{mm} \times 4.6 \mathrm{~mm}, 1.8 \mathrm{~m}$ ) rapid 
resolution column held at $50{ }^{\circ} \mathrm{C}$. Mobile phase was delivered at flow rate of $0.5 \mathrm{~mL} / \mathrm{min}$ (instead of $1 \mathrm{~mL} / \mathrm{min}$ ) in gradient mode ( $0 \mathrm{~min} 30 \% \mathrm{~B}, 12 \mathrm{~min} 70 \% \mathrm{~B}, 18 \mathrm{~min} 100 \% \mathrm{~B}, 24 \mathrm{~min}$ $100 \% \mathrm{~B}$, re-equilibration time $6 \mathrm{~min}$, instead of $0 \mathrm{~min} 30 \% \mathrm{~B}, 6 \mathrm{~min} 70 \% \mathrm{~B}, 9 \mathrm{~min} 100 \% \mathrm{~B}$, $12 \mathrm{~min} 100 \% \mathrm{~B}$, re-equilibration time $3 \mathrm{~min}$ ). Eluted compounds were detected by MS, using the ion source parameters as follows: nebulization gas $\left(\mathrm{N}_{2}\right)$ pressure 40 psi, drying gas $\left(\mathrm{N}_{2}\right)$ flow $9 \mathrm{~L} / \mathrm{min}$ and temperature $350{ }^{\circ} \mathrm{C}$, capillary voltage $4 \mathrm{kV}$, negative polarity. Data were acquired in dynamic MRM mode, using the optimized compound-specific parameters (retention time, precursor ion, product ion, fragmentor voltage, collision voltage). For all the compounds, peak areas were determined using Agilent MassHunter Workstation software Qualitative Analysis (ver. B.03.01). Calibration curves were plotted, and concentrations of samples calculated using the OriginLabs Origin Pro (ver. 9.0) software.

\subsection{Statistical Analysis}

All assays were performed in triplicate. The results were expressed as mean $\pm \mathrm{SD}$. $\mathrm{IC}_{50}$ and $\mathrm{IC}_{25}$ values were determined by the linear regression analysis of RSC (Origin Pro 2016 software, version 9.3). The data that have a normal distribution were subjected to two-way analysis of variance (ANOVA)and multivariate analysis of variance (MANOVA). Tukey's test was used to determine significant differences $(p<0.05)$ between the extracts. Nonparametric Friedman tests and posthoc LSD tests were used for data that do not have a normal distribution. The correlation between antioxidant capacity and total phenols content was established using the Pearson's product-moment correlation (normally distributed data) and Spearman correlation (data that do not have a normal distribution). The statistical analysis was performed using the IBM SPSS Statistics software version 22.0 for Windows.

\section{Results}

\subsection{Inhibition of AChEEnzyme}

The strongest potency was observed for PSH extracts of $S$. commune, where the highest concentration range (1\%) overtakes $\mathrm{IC}_{90}$ (Figure $\left.1 \mathrm{~A}\right)$. Results of AChE inhibition activity (AChEI) of EtOH extracts were presented as $\mathrm{IC}_{50}$ value, owing to the lower inhibition than $\mathrm{PSH}$, which are presented as $\mathrm{IC}_{90}$ values (Figure $1 \mathrm{~B}$ ). The $\mathrm{IC}_{50}$ value of positive control (donepezil) was $87.92 \%$.
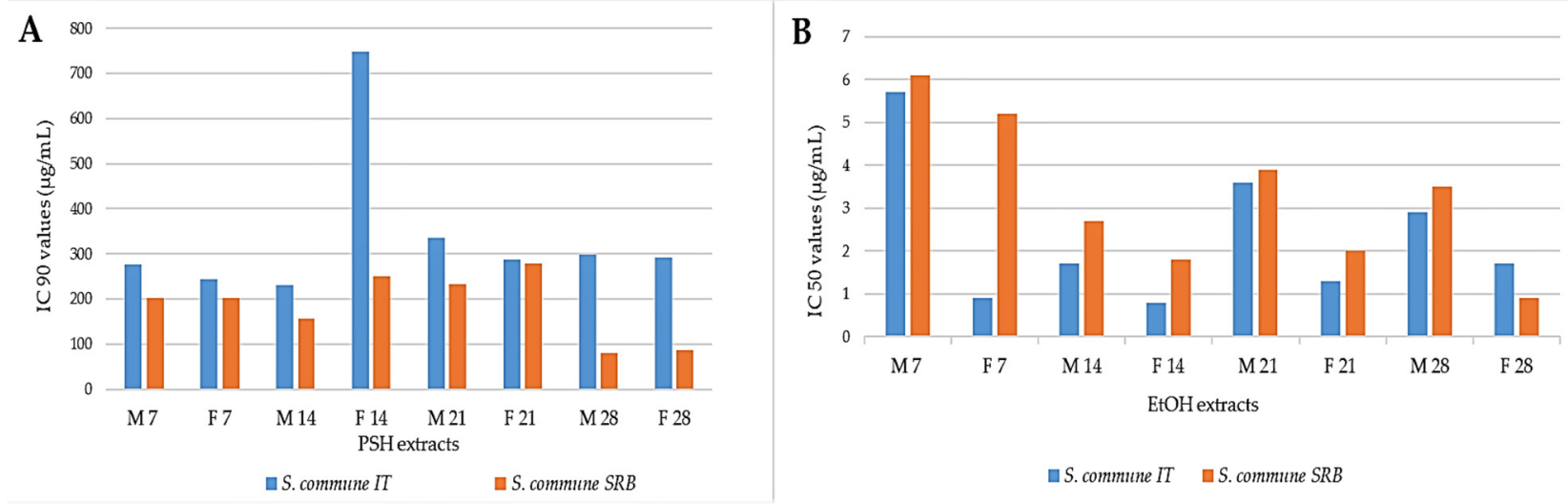

Figure 1. Comparative pre-presentation of acetylcholinesterase (AChE) inhibitory activity of two different isolates (Italy (IIT) and Serbia (SRB)) of S. commune:(A) inhibitory activity of submerged polysaccharide (PSH) extracts presented as IC 90 values $(\mu \mathrm{g} / \mathrm{mL}) ;(\mathbf{B})$ inhibitory activity of EtOH extracts presented as $\mathrm{IC}_{50}$ values $(\mu \mathrm{g} / \mathrm{mL})$.

Different strains of S. commune (IT, SRB) showed different AChEI activity. The PSH extracts of the SRB strain showed higher activity compared to the IT strain, while in EtOH extracts, the opposite was obtained (Figure 1). Among PSH extracts, the highest activity exhibited $\mathrm{M}$ of SRB strain after 28 days of incubation ( $\mathrm{IC}_{90} 79.73 \pm 26.34 \mu \mathrm{g} / \mathrm{mL}$ ), 
while among $\mathrm{EtOH}$, the strongest extract was F of IT strain after 14 days of incubation $\left(\mathrm{IC}_{50} 0.8 \pm 0.6 \mu \mathrm{g} / \mathrm{mL}\right)$.

By comparing the inhibitory activity of $\mathrm{M}$ and $\mathrm{F}$, higher AChEI activity was observed in the F within EtOH extract, while in PSH extracts M was stronger. Among EtOH extracts, differences in activity were related to the incubation period, and the strongest activity was shown after 14 days of incubation, apart from $\mathrm{F}$ extract originating from SRB, which showed the strongest activity after 28 days of incubation. PSH extracts did not show a statistically significant difference (ANOVA, $p<0.05$ ) in inhibition of AChE when it comes to the incubation period, as opposed to EtOH extracts.

\subsection{Determination of Antioxidant Activity \\ 3.2.1. DPPH Assay}

All tested samples exhibited antiradical activity, with PSH being more active (Table 1). Among PSH extracts, the highest ability to capture DPPH radicals was shown by M after 14 days ( $\mathrm{IC}_{50} 14.45 \pm 6.83$ for IT) and 7 days of cultivation ( $\mathrm{IC}_{50} 18.92 \pm 6.12$ for SRB), while within F extracts those incubated 7 days distinguished $\left(\mathrm{IC}_{50} 16.03 \pm 4.30 \mu \mathrm{g} / \mathrm{mL}\right.$ for IT isolate and $\mathrm{IC}_{50} 15.76 \pm 0.63 \mu \mathrm{g} / \mathrm{mL}$ for SRB isolate, respectively).

For EtOH extracts, the AO of $\mathrm{F}$ increased linearly from the 7th to the 21st day when it reached its highest activity $\left(\mathrm{IC}_{50} 55.43 \pm 1.89 \mu \mathrm{g} / \mathrm{mL}\right.$ for IT isolate and $\mathrm{IC}_{50}$ $55.96 \pm 1.31 \mu \mathrm{g} / \mathrm{mL}$ for SRB isolate, respectively), and then on the 28th day, it began to decline for both isolates. Among $\mathrm{M}$ extracts, the analyzed antiradical activity had variations, but nevertheless, on day 14 , they proved to havethe best ability to neutralize free radicals (IC $5049.34 \pm 0.65 \mu \mathrm{g} / \mathrm{mL}$ for IT and $\mathrm{IC}_{50} 74.65 \pm 1.74 \mu \mathrm{g} / \mathrm{mL}$ for SRB, respectively).

\subsubsection{ABTS Assay}

All analyzed samples (PSH and EtOH) showed the ability to "capture" ABTS radicals, with the PSH extracts being more active (Table 1). When we compare the two strains, $\mathrm{F}$ extracts were stronger in IT isolate and $\mathrm{M}$ extracts in SRB isolate. Overall, M extracts exhibited stronger activity compared to the $\mathrm{F}$ in both isolates.

\subsubsection{FRAP Assay}

The ferric reducing ability of $\mathrm{PSH}$ and $\mathrm{EtOH}$ extract for both isolates was evaluated and compared (Table 1). By comparing all extracts, IT strain was more effective, with the exception of one SRB F extract (EtOH, 14 days), which exhibited the greatest activity $(107.86 \pm 12.81 \mathrm{mg} \mathrm{AAE} / \mathrm{g}$ d.w). In all samples, F extracts showed a higher FRAP value than M. Moreover, in both strains, PSH F extracts demonstrated lower activity than EtOH $\mathrm{F}$, as opposed to M extracts, where PSH extracts were stronger. According to statistical analysis (ANOVA, $p<0.05$ ) incubation period did not increase the reduction potential of the extracts.

\subsubsection{SOA Assay}

All tested $\mathrm{EtOH}$ extracts showed the ability to neutralize $\mathrm{O}_{2}{ }^{-}$. SRB strain was more potent compared to IT, while F extracts of both strains showed much higher antiradical activity (Table 2).

\subsubsection{OH Assay}

EtOH extracts of $S$. commune (IT and SRB) showed the best $\mathrm{OH}^{\bullet}$ neutralizing activity after 28 days of incubation $\left(\mathrm{IC}_{25} 10.80 \pm 0.54 \mu \mathrm{g} / \mathrm{mL}\right.$ for F IT, $\mathrm{IC}_{25} 89.69 \pm 0.38 \mu \mathrm{g} / \mathrm{mL}$ for F SRB and $\mathrm{IC}_{25} 85.57 \pm 0.12 \mu \mathrm{g} / \mathrm{mL}$ for M SRB), apart from M extract of IT strain which displayed the highest activity after 7 days $\left(\mathrm{IC}_{25} 20.20 \pm 1.36 \mu \mathrm{g} / \mathrm{mL}\right)$ (Table 2). Summarized, extracts from IT strain were more effective. 


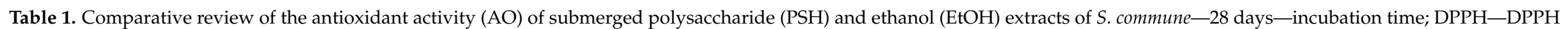
assay; ABTS—ABTS assay; TE-Trolox equivalents; FRAP—FRAP assay; AAE—ascorbic acid equivalents.

\begin{tabular}{|c|c|c|c|c|c|c|c|}
\hline \multirow{2}{*}{\multicolumn{2}{|c|}{$\begin{array}{c}\text { Extracts } \\
\text { S. commune IT }\end{array}$}} & \multicolumn{2}{|c|}{$\mathrm{DPPH}^{1}\left(\mathrm{IC}_{50}\right)(\mu \mathrm{g} / \mathrm{mL})$} & \multicolumn{2}{|c|}{ ABTS $^{2}$ (mg TE/g d.w.) } & \multicolumn{2}{|c|}{ FRAP $^{3}$ (mg AAE/g d.w.) } \\
\hline & & $\mathrm{PSH}$ & $\mathrm{EtOH}$ & $\mathrm{PSH}$ & $\mathrm{EtOH}$ & $\mathrm{PSH}$ & $\mathrm{EtOH}$ \\
\hline \multirow{4}{*}{$\mathrm{F}$} & 7 days & $16.03 \pm 4.30^{a}$ & $72.65 \pm 9.15^{a}$ & $6.64 \pm 0.66^{\mathrm{a}}$ & $5.17 \pm 0.03^{a}$ & $65.11 \pm 6.27^{a}$ & $42.58 \pm 3.47^{\mathrm{a}}$ \\
\hline & 14 days & $107.94 \pm 2.36^{a}$ & $63.67 \pm 2.65^{a}$ & $8.20 \pm 0.94^{a}$ & $4.95 \pm 0.41^{\mathrm{a}}$ & $66.73 \pm 12.11^{a}$ & $99.00 \pm 2.73^{a}$ \\
\hline & 21 days & $74.76 \pm 19.70^{a}$ & $55.43 \pm 1.89^{a}$ & $5.69 \pm 0.52^{a}$ & $5.27 \pm 0.22^{a}$ & $82.96 \pm 0.94^{a}$ & $91.65 \pm 0.96^{\mathrm{a}}$ \\
\hline & 28 days & $189.81 \pm 7.96^{\mathrm{a}}$ & $69.15 \pm 3.98^{a}$ & $2.86 \pm 1.30^{\mathrm{a}}$ & $3.38 \pm 0.06^{\mathrm{a}}$ & $28.44 \pm 7.72^{\mathrm{a}}$ & $47.82 \pm 5.28^{a}$ \\
\hline \multirow{4}{*}{ M } & 7 days & $94.89 \pm 8.41^{\mathrm{a}}$ & $82.69 \pm 1.93^{a}$ & $5.16 \pm 1.63^{\mathrm{a}}$ & $5.29 \pm 0.05^{\mathrm{a}}$ & $40.03 \pm 3.41^{\mathrm{a}}$ & $66.39 \pm 3.84^{\mathrm{a}}$ \\
\hline & 14 days & $14.45 \pm 6.83^{a}$ & $49.34 \pm 0.65^{a}$ & $1.63 \pm 1.71^{a}$ & $5.20 \pm 0.08^{a}$ & $6.49 \pm 7.40^{a}$ & $81.30 \pm 1.98^{a}$ \\
\hline & 21 days & $85.39 \pm 1.61^{a}$ & $120.63 \pm 3.29^{a}$ & $7.49 \pm 0.67^{a}$ & $5.84 \pm 0.06^{\mathrm{a}}$ & $79.12 \pm 10.77^{a}$ & $14.22 \pm 1.32^{\mathrm{a}}$ \\
\hline & 28 days & $93.48 \pm 0.01^{\mathrm{a}}$ & $105.39 \pm 1.66^{a}$ & $5.12 \pm 0.39^{a}$ & $4.85 \pm 0.19^{a}$ & $33.67 \pm 5.35^{a}$ & $32.46 \pm 1.27^{\mathrm{a}}$ \\
\hline \multicolumn{8}{|c|}{ S. commune SRB } \\
\hline \multirow{3}{*}{$\mathrm{F}$} & 7 days & $15.76 \pm 0.63^{a}$ & $70.86 \pm 2.52^{b}$ & $2.60 \pm 0.14^{\mathrm{a}}$ & $3.80 \pm 0.08^{a}$ & $0.28 \pm 0.09^{b}$ & $61.81 \pm 4.78^{a, c}$ \\
\hline & 14 days & $32.42 \pm 3.09^{a}$ & $53.61 \pm 2.32^{b}$ & $7.40 \pm 0.19^{a}$ & $3.26 \pm 0.96^{\mathrm{a}}$ & $9.69 \pm 3.67^{b}$ & $107.86 \pm 12.8^{a, c}$ \\
\hline & 21 days & $30.18 \pm 2.25^{\mathrm{a}}$ & $55.96 \pm 1.31^{b}$ & $7.62 \pm 0.62^{a}$ & $4.65 \pm 0.31^{a}$ & $57.10 \pm 2.35^{b}$ & $89.97 \pm 12.81^{\mathrm{a}, \mathrm{c}}$ \\
\hline \multirow{4}{*}{$\mathrm{M}$} & 7 days & $18.92 \pm 6.12^{a}$ & $377.71 \pm 14.85^{\mathrm{b}}$ & $7.78 \pm 0.41^{a}$ & $6.01 \pm 0.07^{\mathrm{a}}$ & $20.89 \pm 1.67^{b}$ & $11.44 \pm 0.84^{\mathrm{a}, \mathrm{d}}$ \\
\hline & 14 days & $71.55 \pm 3.43^{\mathrm{a}}$ & $74.65 \pm 1.74^{b}$ & $3.17 \pm 0.44^{\mathrm{a}}$ & $3.02 \pm 0.10^{a}$ & $9.55 \pm 0.51^{b}$ & $5.99 \pm 0.20^{\mathrm{a}, \mathrm{d}}$ \\
\hline & 21 days & $69.13 \pm 4.24^{\mathrm{a}}$ & $164.28 \pm 2.52^{b}$ & $2.30 \pm 0.31^{\mathrm{a}}$ & $5.43 \pm 0.53^{a}$ & $5.61 \pm 1.83^{b}$ & $10.77 \pm 1.05^{\mathrm{a}, \mathrm{d}}$ \\
\hline & 28 days & $51.41 \pm 11.27^{\mathrm{a}}$ & $137.5 \pm 5.87^{b}$ & $2.14 \pm 0.35^{\mathrm{a}}$ & $5.49 \pm 0.23^{a}$ & $0.90 \pm 1.91^{b}$ & $10.91 \pm 0.46^{\mathrm{a}, \mathrm{d}}$ \\
\hline
\end{tabular}

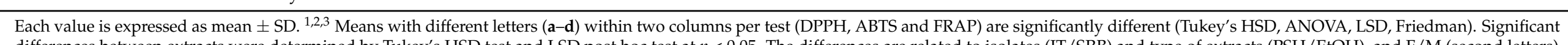

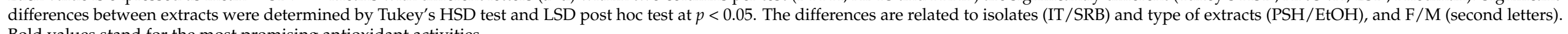
Bold values stand for the most promising antioxidant activities. 


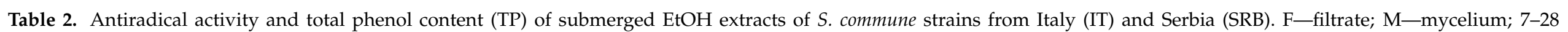
days-Incubation time; GAE-gallic acid equivalents.

\begin{tabular}{|c|c|c|c|c|c|}
\hline \multicolumn{2}{|c|}{ Extracts } & \multirow{2}{*}{$\frac{\text { SOA }\left(\mathrm{IC}_{50}\right)(\mu \mathrm{g} / \mathrm{mL})}{\text { S. commune IT }}$} & \multirow[t]{2}{*}{$\mathrm{OH}\left(\mathrm{IC}_{25}\right)(\mu \mathrm{g} / \mathrm{mL})$} & \multirow[t]{2}{*}{ NO $\left(\mathrm{IC}_{25}\right)(\mu \mathrm{g} / \mathrm{mL})$} & \multirow[t]{2}{*}{ TP (mgGAE/g.d.w.) } \\
\hline & & & & & \\
\hline \multirow{4}{*}{$\mathrm{F}$} & 7 days & $526.68 \pm 152.45^{\mathrm{a}}$ & $103.02 \pm 12.23^{\mathrm{a}}$ & $614.02 \pm 14.79^{a}$ & $69.48 \pm 1.00^{\mathrm{a}}$ \\
\hline & 14 days & $652.14 \pm 6.56^{\mathrm{a}}$ & $124.27 \pm 7.00^{\mathrm{a}}$ & $965.43 \pm 129.75^{a}$ & $75.23 \pm 1.04^{\mathrm{a}}$ \\
\hline & 21 days & $90 \%{ }^{1}$ & $110.85 \pm 2.31^{a}$ & $707.05 \pm 34.84^{a}$ & $77.52 \pm 0.97^{a}$ \\
\hline & 28 days & $90 \%^{1}$ & $10.80 \pm 0.54^{a}$ & $1161.41 \pm 48.90^{a}$ & $68.70 \pm 0.30^{\mathrm{a}}$ \\
\hline \multirow{4}{*}{ M } & 7 days & $602.41 \pm 0.01^{\mathrm{a}}$ & $20.20 \pm 1.36^{a}$ & $788.80 \pm 36.36^{a}$ & $53.49 \pm 1.97^{\mathrm{a}}$ \\
\hline & 14 days & $216.98 \pm 45.84^{a}$ & $228.36 \pm 3.25^{a}$ & $1182.78 \pm 36.35^{\mathrm{a}}$ & $76.65 \pm 1.30^{a}$ \\
\hline & 21 days & $634.14 \pm 38.25^{a}$ & $44.29 \pm 4.20^{\mathrm{a}}$ & n.a. ${ }^{2}$ & $42.74 \pm 1.40^{\mathrm{a}}$ \\
\hline & 28 days & $492.92 \pm 125.11^{\mathrm{a}}$ & $84.74 \pm 2.36^{\mathrm{a}}$ & n.a. ${ }^{2}$ & $70.01 \pm 0.65^{\mathrm{a}}$ \\
\hline & & S. commune SRB & & & \\
\hline \multirow{3}{*}{$\mathrm{F}$} & 7 days & $635.74 \pm 8.99^{a}$ & $494.34 \pm 59.08^{a}$ & $1794.48 \pm 13.21^{a}$ & $84.60 \pm 1.64^{a}$ \\
\hline & 14 days & $90 \%{ }^{1}$ & $257.92 \pm 0.01^{\mathrm{a}}$ & $<\mathrm{IC}_{25}{ }^{3}$ & $81.93 \pm 0.81^{a}$ \\
\hline & 21 days & $90 \%{ }^{1}$ & $261.38 \pm 0.01^{\mathrm{a}}$ & $<\mathrm{IC}_{25}{ }^{3}$ & $78.27 \pm 1.75^{\mathrm{a}}$ \\
\hline \multirow{4}{*}{ M } & 7 days & $161.60 \pm 2.06^{a}$ & $170.57 \pm 0.35^{\mathrm{a}}$ & $737.12 \pm 32.91^{\mathrm{a}}$ & $40.22 \pm 0.82^{\mathrm{a}}$ \\
\hline & 14 days & $253.14 \pm 17.33^{a}$ & $163.94 \pm 19.22^{\mathrm{a}}$ & $145.88 \pm 2.83^{a}$ & $82.62 \pm 0.99^{a}$ \\
\hline & 21 days & $429.60 \pm 44.01^{\mathrm{a}}$ & $89.45 \pm 0.01^{\mathrm{a}}$ & $785.34 \pm 39.03^{a}$ & $63.28 \pm 1.28^{a}$ \\
\hline & 28 days & $218.01 \pm 13.59^{a}$ & $85.57 \pm 0.12^{a}$ & $112.19 \pm 19.73^{a}$ & $2.09 \pm 0.06^{\mathrm{a}}$ \\
\hline
\end{tabular}

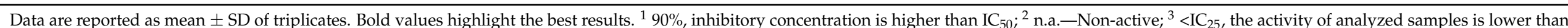
$\mathrm{IC}_{25}$. ${ }^{a}$ In each column different letters, mean significant differences (Tukey's HSD test at $\left.p<0.05\right)$. The difference is related to isolate (IT/SRB) and type of samples (F/M). 


\subsubsection{NO Assay}

Among analyzed EtOH extracts, both isolates demonstrated moderate radical scavenging capacity, while some extracts were inactive or the activity of analyzed samples waslower than $\mathrm{IC}_{25}$ (Table 2).

\subsection{Determination of Antibacterial Activity}

Studies on the MIC and MBC for EtOH extracts demonstrated that only two extracts among all from SRB strain exhibited antibacterial activity, while IT strain was not active. The F extract of SRB strain after 21 days of cultivation demonstrated the highest antimicrobial activity (MIC and $\mathrm{MBC}<0.31 \%$ ) against E. coli, B. cereus and S. aureus, while the lowest was exhibited against P. aeruginosa (MIC and MBC 5\%). F extract of SRB strain after 14 days of incubation demonstrated antibacterial activity (MIC $0.62 \%$ and MBC $0.31 \%$ ) only against E. coli.

\subsection{Total Phenol (TP) Content and Correlation Analysis}

TP content is presented in Table 2. The amount of TP in both strains was high and rather similar; nonetheless, SRB extracts showed a higher value $(84.60 \pm 1.64 \mathrm{mg}$ GAE $/ \mathrm{g}$ d.w. for F and $82.62 \pm 0.99 \mathrm{mg} \mathrm{GAE} / \mathrm{g}$ d.w. for M, respectively). In addition, F extracts of both strains demonstrated higher TP content compared to M. Correlation analysis was performed to find out how $\mathrm{AO}$ of extracts is related to their TP content. A negative correlation between antioxidant properties and TP content was noticed in the ABTS assay of SRB extracts $\left(\mathrm{r}^{2}-0.79\right)$, while a close correlation $(p<0.05)$ in $\mathrm{OH}$ assay in both isolates $\left(\mathrm{r}^{2} 0.81\right.$ for IT and $\mathrm{r}^{2} 0.71$ for SRB) was obtained. In addition, a positive correlation was detected between FRAP assay and TP content $\left(\mathrm{r}^{2} 0.69\right.$ for IT).

\subsection{Chemical Characterization of Extracts}

\subsubsection{FTIR Analysis}

The spectra of all PSH samples investigated (Figure 2 (A-D) showed peaks characteristic for the presence of predominantly polysaccharides molecules, small quantities of protein and some aromatics. In all samples, the intensive sharp absorption at $1078-1080 \mathrm{~cm}^{-1}$ was characteristic of the presence of $\beta$-glucan due to O-substituted glucose residues [36]. The strong absorption at about $1050 \mathrm{~cm}^{-1}$ in each sample indicated that these polysaccharides had pyranose rings [37]. An intensive absorption band with a maximum at $1640 \mathrm{~cm}^{-1}$ corresponded to the characteristic frequency of protein as well as to the bending vibration $\mathrm{O}-\mathrm{H}$ of associated water. This strong vibration was overlapped by specific absorption of aromatics $(\mathrm{C}=\mathrm{C}$ and $\mathrm{C}=\mathrm{O}$ stretch vibrations) and indicated the presence of phenolic compounds [38]. Frequencies at region $1410-1310 \mathrm{~cm}^{-1}$ corresponded to O-H groups of phenolics, too. In the anomeric region $\left(950-700 \mathrm{~cm}^{-1}\right)$, the characteristic weak absorption at $890 \mathrm{~cm}^{-1}$ in all samples corresponded to the presence of $\beta$-glycosidic linkages $(\mathrm{C} 1-\mathrm{H}$ deformation mode) [39]. Furthermore, the additional weak frequency at $935 \mathrm{~cm}^{-1}$ in B and C samples was also related to $\beta$-glycosidic bonds [40].

The FTIR spectrum of the EtOH extract (Figure S3) showed absorption bands characteristic for the carbohydrate polymers as well as proteins and polyphenolic compounds [41]. The bands in the region $1310-1410 \mathrm{~cm}^{-1}$ correlate with the valence vibrations of the $\mathrm{OH}$ groups of phenolic compounds. Among F samples of SRB extracts, the intensity of individual absorption bands was different. Namely, the intensity of bands in the region $1000-1200 \mathrm{~cm}^{-1}$ related to valence vibrations of CO and CC polysaccharide structures is reduced compared to the intensities of other absorption peaks. This indicates a decrease in the proportion of carbohydrate polymers relative to other compounds present in the mixture (e.g., phenols). The absence of the characteristic ester band in the region $1730-1740 \mathrm{~cm}^{-1}$ in all analyzed FTIR spectra indicates that the examined extracts do not contain uronic acids as part of their structural characteristics. 


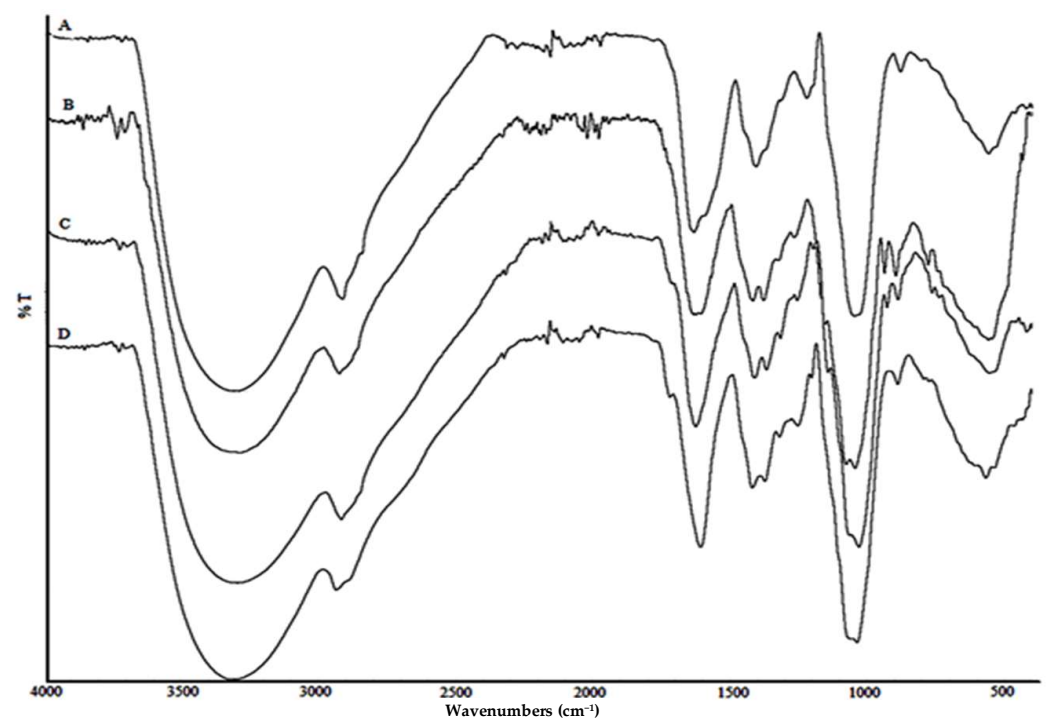

Figure 2. Fourier-transform infrared spectroscopy of polysaccharide samples isolated from S. commune. Type of extracts examined: A-filtrate, 14 days, F IT; B-mycelium, 14 days, M IT: C-mycelium, 14 days, M SRB; D-filtrate, 28 days, F SRB.

\subsubsection{Monosaccharide Composition}

The presence of a large amount of D-glucose with smaller amounts of D-galactose and traces of D-mannose was confirmed in investigated hydrolysates by PC.

\subsubsection{LC-MS/MS Analysis}

In all examined $\mathrm{PSH}$ and $\mathrm{EtOH}$, among 45 investigated phenolics, 4 compounds were quantified using LC-MS/MS procedure (Table 3). Other phenolic compounds were above the limit of detection but lower than the limit of quantification (Table S1). Three hydroxybenzoic acids and one cyclohexane carboxylic acid were detected. $p$-Hydroxybenzoic acid was detected in all investigated samples, while richer content was found in IT isolates $(64.92 \mu \mathrm{g} / \mathrm{g}$ in total). The most abundant compound was gallic acid found in SRB F extract $(75.77 \mu \mathrm{g} / \mathrm{g})$. In comparison, EtOH extracts contained most of the analyzed phenolic acids, whereas F extracts showed higher phenolic content than M (167.55 $\mu \mathrm{g} / \mathrm{g}$ in total). 
Table 3. Determined concentrations of selected phenolic compounds using LC-MS/MS technique in examined polysaccharide and ethanolic extracts ( $\mu$ g/g.d.w.).

\begin{tabular}{|c|c|c|c|c|}
\hline \multirow{3}{*}{ Extracts } & \multicolumn{4}{|c|}{ Class of Analyzed Compounds } \\
\hline & \multicolumn{3}{|c|}{ Hydroxybenzoic Acids } & \multirow{2}{*}{$\begin{array}{c}\text { Cyclohexane Carboxylic Acid } \\
\text { Quinic Acid }\end{array}$} \\
\hline & $p$-Hydroxybenzoic Acid & Protocatechuic Acid & Gallic Acid & \\
\hline \multicolumn{5}{|l|}{ PSH } \\
\hline IT F 7 & 5.50 & 3.17 & $<12.2^{*}$ & $<3.05^{*}$ \\
\hline IT M 7 & 1.87 & $<1.525 *$ & $<12.2^{*}$ & $<3.05^{*}$ \\
\hline IT M 14 & 8.28 & $<1.525 *$ & $<12.2 *$ & $<3.05^{*}$ \\
\hline SRB F 7 & $<1.525^{*}$ & $<1.525 *$ & $<12.2^{*}$ & 4.29 \\
\hline \multicolumn{5}{|l|}{ EtOH } \\
\hline IT F 14 & 3.81 & $<1.525 *$ & $<12.2^{*}$ & 13.24 \\
\hline IT F 21 & 9.51 & $<1.525 *$ & $<12.2 *$ & $<3.05^{*}$ \\
\hline IT M 14 & 4.10 & $<1.525^{*}$ & $<12.2^{*}$ & 8.57 \\
\hline IT M 21 & 9.66 & $<1.525 *$ & $<12.2^{*}$ & $<3.05^{*}$ \\
\hline IT M 28 & 22.19 & 5.41 & $<12.2^{*}$ & 4.82 \\
\hline SRB F 7 & 12.14 & $<1.525 *$ & $<12.2 *$ & 15.51 \\
\hline SRB F 14 & 3.77 & $<1.525 *$ & 75.77 & $<3.05^{*}$ \\
\hline SRB F 21 & 11.25 & 1.90 & $<12.2^{*}$ & $<3.05^{*}$ \\
\hline SRB F 28 & 7.69 & $<1.525 *$ & $<12.2^{*}$ & $<3.05^{*}$ \\
\hline SRB M 7 & 5.93 & $<1.525^{*}$ & $<12.2^{*}$ & 19.52 \\
\hline SRB M 14 & 5.94 & $<1.525^{*}$ & $<12.2 *$ & 20.06 \\
\hline SRB M 21 & 6.52 & $<1.525 *$ & $<12.2 *$ & 5.49 \\
\hline
\end{tabular}

Bold number: the amount of quantified phenolic compounds in examined extracts. ${ }^{*}$ Number: detected compound-Peak observed, concentration is lower than the LoQ (limit of quantification) but higher than the LoD (limit of detection). PSH-polysaccharide extracts; $\mathrm{EtOH}$ — ethanolic extracts; IT—isolate from Italy; SRB—isolate from Serbia; F—filtrate; M—mycelium; 7, 14, 21, 28—days of incubation.

\section{Discussion}

Inhibition of AChE enzyme was determined and compared for PSH and EtOH extracts of both investigated strains of S. commune (Figure 1). All PSH extracts, both M and F, exhibited significantly strong activity, hence expressed as $\mathrm{IC}_{90}$, which is comparable to the activity of a commercially approved AD drug donepezil (87.92\%). Though some subtle distinction exists, the FTIR spectrum of PSH extracts (Figure 2) indicates that there are no significant differences in the composition of the $\mathrm{F}$ and $\mathrm{M}$, owing to the mixture of polysaccharide fraction, probably schizophyllan structure [42], which is further expressed by their very similar AChE inhibitory activity.

Among EtOH extracts, stronger AChEI was observed for IT F extracts after 14 days of cultivation, while among PSH extracts, SRB M expressedgreater inhibition potential after 28 days of incubation. Furthermore, the incubation period did not show a statistically significant difference in PSH extracts (ANOVA, $p<0.05$ ), while among EtOH incubation period had a greater impact $(p=0.04)$ on the AChEI activity, with 14 and 28 days being the highest (Figure 1B).This can be explained by the highest production of secondary metabolites, including phenolics in submerged cultivation in the stationary phase of cultivation when nutritive components are limited LC-MS/MS analysis (Table 3) revealed that within strongest EtOH extracts beside $p$-hydroxybenzoic acid, a high amount of quinic acid were found. Though in a previous study, quinic acid did not inhibit the AChE enzyme [43], it was shown that $p$-hydroxybenzoic acid exhibited lower inhibitory activity compared to 2-hydroxybenzoic acid [44]. The concentration of esculetin, a derivative of coumarin, in all examined submerged extracts of $S$. commune was higher than the limit of detection, 
while in Coprinus comatus, its presence in both mycelia and filtrate was recorded in a higher amount using HPLC-MS/MS procedure [45]. Ali et al. [46] demonstrated strong AChEI activity of this compound isolated from plants, and its AO was reported [44]. On the other hand, polysaccharides originating from mushrooms could be significant in AD therapy since in vivo experiments indicate that they might improve learning and memory [47]. Furthermore, the FTIR spectrum of PSH and EtOH extracts (Figure 2 and Figure S3) showed the presence of predominantly polysaccharide molecules next to proteins and phenolic compounds. Shizophyllan, $\beta-1,3$ beta-glucan with $\beta-1,6$ branching, a potent polysaccharide found in S. commune, may play an important role since PSH extracts exhibited high AChE inhibitory activity, opposite to PSH samples for Trametes versicolor, extracted after the same procedure, where activity was not detected [10]. In addition, EtOH samples demonstrated lower AChE inhibitory activity (44.35\%) [10], compared to our results (Figure 1), while Abdullah et al. [48] recorded weak AChEI activity of hot water extracts of S. commune $\left(\mathrm{IC}_{50} 0.320 \pm 0.070 \mathrm{mg} / \mathrm{mL}\right)$.

$\mathrm{AO}$ of PSH and $\mathrm{EtOH}$ extracts was evaluated in vitro using standard antioxidant assays (Tables 1 and 2). Based on Table 1, there are statistically significant differences (ANOVA and Friedman, $p<0.05$ ) among PSH and EtOH samples from SRB in DPPH and FRAP assays. EtOH samples from $\mathrm{OH}$ assay stands out since in $\mathrm{NO}$ and SOA tests, except $F$ extracts, much lower antiradical activity was recorded (Table 2). The highest activity of $F$ extracts (IT, 28 days) showed significant value ( IC $_{25} 10.80 \pm 0.54 \mu \mathrm{g} / \mathrm{mL}$ ) while among SRB samples, the activity of F and $\mathrm{M}\left(\mathrm{IC}_{25} 89.69 \pm 0.38 \mu \mathrm{g} / \mathrm{mL}\right.$ andIC $2585.57 \pm 0.12 \mu \mathrm{g} / \mathrm{mL}$, respectively) for the same incubation period was almost eight times lower.

Results of $\mathrm{OH}$ assays for EtOH extracts are comparable with TP content since a high positive correlation was obtained $\left(\mathrm{r}^{2} 0.81\right.$ for IT and $\mathrm{r}^{2} 0.71$ for SRB). Moreover, these results suggest the potential use of this mushroom for the prevention of oxidative stress since $\mathrm{OH}$ is physiologically active and toxic [28]. DPPH assay did not show a statistically significant difference in correlation with TP content, although previous data from submerged methanol samples of Coprinus species demonstrated a positive correlation, which may be due to the application of different solvents [49].EtOH and $\mathrm{MeOH}$ extracts of S. commune showed three times lower anti-DPPH activity $\left(\mathrm{IC}_{50} 153.1 \pm 0.02 \mu \mathrm{g} / \mathrm{mL}\right.$ ) [48], while EtOH extract of the same species from India demonstrated two times higher RSC $\mathrm{IC}_{50} 18.56 \mu \mathrm{g} / \mathrm{mL}$ [50], compared to the strongest reported herein for EtOH extracts ( $\mathrm{IC}_{50}$ $49.34 \pm 0.65 \mu \mathrm{g} / \mathrm{mL}$ ). EtOH extracts from submerged fermented mycelium (10 days) demonstrated stronger scavenging capacity as reported by Tripathi and Tiwary with $\mathrm{IC}_{50} 31.40 \pm 0.05 \mu \mathrm{g} / \mathrm{mL}$ [51]. In other studies, lower scavenging capacity and reducing the effect of fruiting body extracts were recorded as well, while TP content varied from significantly reduced value $(1.72 \pm 0.05 \mathrm{mg} \mathrm{GAE} / \mathrm{g}$ d.w. and $2.99 \pm 0.04 \mathrm{mg} \mathrm{GAE} / \mathrm{g}$ d.w. $)$ to twice the lower value (41.07 $\pm 0.60 \mathrm{mg} \mathrm{GAE} / \mathrm{g}$ d.w.) [52-54]. Nevertheless, submerged extracts of S. commune from Thailand showed higher DPPH activity (inhibition of DPPH ranged from 34.29 to $81.00 \%$ ) with fermentation broth being twice as active [55], which is in accordance with our study and refers to the production of secondary metabolites during submerged cultivation. Given what has been said, a higher amount of TPcontent in F extracts (Table 2) quantified by LC-MS/MS (Table 3) indicates that fungal cells represent small bio-factories since various classes of metabolites can be produced during the same procedure of submerged cultivation. In comparison, $\mathrm{PSH}$ and EtOH extracts of T. versicolor exhibited RSC activity 50 times lower [10], which impliesthat besides phenolic compounds, primary metabolites, including polysaccharides, may play a role in AO.

LC-MS/MS procedure of extracts from the fruiting body of this mushroom species detected only protocatechuic and hydroxybenzoic acids in higher amounts [56], while lower amounts of various phenolic compounds were detected (Table S1). This quantitative and qualitative variability is expected considering the different origins of fungal growth (mycelia, extracellular media) during submerged cultivation can produce different classes and concentrations of metabolites. According to growth curves, SRB strain (Figures S1 and S2) has rapid growth and reached the critical point of entry in secondary 
metabolism much earlier (14 days) than IT strain, when a very high concentration of gallic acid was observed. This can explain high DPPH and FRAP activities for SRB strain as well [57]. IT strain expressed critical points between 21 and 28 days (Figure S1) when different phenolic compounds were detected. All confirmed phenolic compounds (Table 3) are proven antioxidants [58,59], whereas LC-MS/MS analysis demonstrated higher phenolic content in EtOH extracts. Hence, the observed abilities of EtOH extracts may be explained by the presence of secondary metabolites, while primary metabolites may be responsible for high RSC activity among PSH extracts.

Antibacterial activity was very low as only two extracts showed activity. In a previous study, methanolic extract of culture filtrate incubated in submerged conditions for 10 days was active against two Gram-positive bacteria (S. aureus and B. subtilis) [51], which is in accordance with results from this study, since only F extracts of SRB strain showed moderate antibacterial activity.LC-MS/MS analysis and literature data both imply that gallic acid, protocatechuic acid and esculetin may be responsible for antibacterial activity since these compounds can inhibit the growth of E. coli [59-62]. Nonetheless, extracellular pigment melanin from S. commune was active against E. coli as well [63], suggesting a possible synergy effect.

Findings from this study suggest that different compounds, both primary and secondary, could be responsible for inhibition of AChE enzyme as well as for detected AO and antibacterial activities that strongly point out to a likelihood of synergistic activity of compounds in the extracts [16]. Based on observed AChEI activity, different geographical locations (strain origin-IT, SRB) from which the fungal strains were collected may affect the activity and the production of various metabolites probably due to different environmental factors that contribute to the biochemical patterns of the specific genotype (strain).

\section{Conclusions}

To the best of our knowledge, this is the first report describing the AChE inhibitory activity of PSH extracts of submerged extracts of $S$. commune. Most of the analyzed submerged samples exhibited AO, which is in direct relation to the characteristics of strain's growth as it can point to the moment of entry in secondary metabolism, while in AChEIactivity, PSH extracts demonstrated remarkable results and represent first data for this species. Taken all together, PSH extracts obtained significant AO within samples incubated for 7 days, opposite to EtOH extracts where a 14- and 21-day cultivation period stood out, which was in accordance with LC-MS/MS phenolic analysis. Differences in activities between two isolates and different types of extracts, together with variations of phenolics content, indicate the important role of both genetic and environmental factors in metabolite production, as well as possible synergistic effect of primary and secondary metabolites. This study introduced $S$. commune as a potential natural antioxidant producer and indicated that the submerged fermentation might serve as an effective alternative method for producing bioactive agents, e.g., pharmaceuticals and nutraceuticals. In summary, this ubiquitous mushroom species should be considered as a valuable alternative source for future palliative therapy of AD.

Supplementary Materials: The following are available online at https:/ www.mdpi.com/2309-608 X/7/2/115/s1, Figure S1: Growth curve of mycelia and lyophilized filtrate for S. commune isolate from Italy (IT); Figure S2: Growth curve of mycelia and lyophilized filtrate for S. commune isolate from Serbia (SRB); Figure S3: Fourier-transform infrared spectroscopy of ethanol samples of S. commune isolates from Serbia (SRB) and Italy (IT); Table S1: Determined concentrations of phenolic compounds using LC-MS/MS technique isexamined polysaccharide and ethanolic extracts ( $\mu \mathrm{g} / \mathrm{g})$.

Author Contributions: Conceptualization, J.M., M.K., A.Z., G.V. and M.R.; methodology, M.K., J.M. and M.R.; validation, M.K., M.R., F.P. and J.M., formal analysis, J.M.; investigation, M.L.G., F.P., J.M., N.K., M.R., S.B. and D.J.; resources, M.R., M.K., D.J. and S.B.; data curation, M.L.G., J.M. and M.R.; writing — original draft preparation, J.M.; writing—review and editing, M.K., A.Z. and G.V.; 
visualization, J.M. and N.K.; supervision, M.K. All authors have read and agreed to the published version of the manuscript.

Funding: This research was kindly supported by The Ministry of Education, Science and Technological Development of the Republic of Serbia, 10.13039/501100004564 [Research Grant No. III43002 and OI172,058].

Institutional Review Board Statement: The study was conducted according to the guidelines of the Declaration of Helsinki, and approved by the Institutional Review Board.

Data Availability Statement: Not applicable.

Acknowledgments: Authors would like to express sincere gratitude to Principal research fellow Boris Pejin.

Conflicts of Interest: The authors declare no conflict of interest. The funders had no role in the design of the study; in the collection, analyses, or interpretation of data; in the writing of the manuscript, or in the decision to publish the results.

\section{References}

1. Dulay, R. Antioxidant activity and total phenolic content of Volvariellavolvacea and Schizophyllum commune mycelia cultured in indigenous liquid media. Mycosphere 2016, 7, 131-138. [CrossRef]

2. Veurink, G.; Perry, G.; Singh, S.K. Role of antioxidants and a nutrient rich diet in Alzheimer's disease: AD and Nutraceuticals. Open Biol. 2020, 10. [CrossRef] [PubMed]

3. Moneim, A.E.A. Oxidant/Antioxidant Imbalance and the Risk of Alzheimer's Disease. Curr. Alzheimer Res. 2015, 12, 335-349. [CrossRef] [PubMed]

4. Nunomura, A.; Perry, G.; Aliev, G.; Hirai, K.; Takeda, A.; Balraj, E.K.; Jones, P.K.; Ghanbari, H.; Wataya, T.; Shimohama, S.; et al. Oxidative Damage Is the Earliest Event in Alzheimer Disease. J. Neuropathol. Exp. Neurol. 2001, 60, 759-767. [CrossRef]

5. Jomova, K.; Vondrakova, D.; Lawson, M.; Valko, M. Metals, oxidative stress and neurodegenerative disorders. Mol. Cell. Biochem. 2010, 345, 91-104. [CrossRef]

6. Chopra, K.; Misra, S.; Kuhad, A. Current perspectives on pharmacotherapy of Alzheimer's disease. Expert Opin. Pharmacother. 2011, 12, 335-350. [CrossRef]

7. Pinho, B.R.; Ferreres, F.; Valentão, P.; Andrade, P.B. Nature as a source of metabolites with cholinesterase-inhibitory activity: An approach to Alzheimer's disease treatment. J. Pharm. Pharmacol. 2013, 65, 1681-1700. [CrossRef]

8. Hostettmann, K.; Borloz, A.; Urbain, A.; Marston, A. Natural Product Inhibitors of Acetylcholinesterase. Curr. Org. Chem. 2006, 10, 825-847. [CrossRef]

9. Moniruzzaman, A.; Hossain, S.; Sarker, J.; Rahman, S.M.A.; Rashid, M.; Rahman, M. In vitro antioxidant and cholinesterase inhibitory activities of methanolic fruit extract of Phyllanthus acidus. BMC Complement. Altern. Med. 2015, 15, 403. [CrossRef]

10. Janjušević, L.; Karaman, M.; Šibul, F.; Tommonaro, G.; Iodice, C.; Jakovljević, D.; Pejin, B. The lignicolous fungus Trametes versicolor (L.) Lloyd (1920): A promising natural source of antiradical and AChE inhibitory agents. J. Enzym. Inhib. Med. Chem. 2017, 32, 355-362. [CrossRef]

11. Su, J.; Liu, H.; Guo, K.; Chen, L.; Yang, M.; Chen, Q. Research Advances and Detection Methodologies for Microbe-Derived Acetylcholinesterase Inhibitors: A Systemic Review. Molecules 2017, 22, 176. [CrossRef] [PubMed]

12. Kozarski, M.; Klaus, A.; Niksic, M.; Jakovljevic, D.; Helsper, J.P.; Van Griensven, L.J. Antioxidative and immunomodulating activities of polysaccharide extracts of the medicinal mushrooms Agaricusbisporus, Agaricusbrasiliensis, Ganoderma lucidum and Phellinus linteus. Food Chem. 2011, 129, 1667-1675. [CrossRef]

13. Zhang, M.; Cui, S.; Cheung, P.; Wang, Q. Antitumor polysaccharides from mushrooms: A review on their isolation process, structural characteristics and antitumor activity. Trends Food Sci. Technol. 2007, 18, 4-19. [CrossRef]

14. Mahmoud, M.G.; Ibrahim, A.Y.; Asker, M.M.S.; El Sayed, O.H. Therapeutic potential and structural elucidation of a water-soluble polysaccharide of a wild edible mushroom Agaricusbisporus against neurodegenerative disease, Alzheimer. World J. Pharm. Sci. 2014, 2, 1136-1145.

15. Phan, C.-W.; David, P.; Vikineswary, S. Edible and Medicinal Mushrooms: Emerging Brain Food for the Mitigation of Neurodegenerative Diseases. J. Med. Food. 2017, 20, 1-10. [CrossRef]

16. Karaman, M.; Stahl, M.; Vulić, J.; Vesić, M.; Čanadanović-Brunet, J. Wild-growing lignicolous mushroom species as sources of novel agents with antioxidative and antibacterial potentials. Int. J. Food Sci. Nutr. 2014, 65, 311-319. [CrossRef]

17. Umeo, S.; Souza, G.; Rapachi, P.; Garcia, D.; Paccola-Meirelles, L.; Valle, J.S.D.; Colauto, N.; Linde, G. Short Communication Screening of basidiomycetes in submerged cultivation based on antioxidant activity. Genet. Mol. Res. 2015, 14, 9907-9914. [CrossRef]

18. Ohm, R.A.; De Jong, J.F.; Lugones, L.G.; Aerts, A.; Kothe, E.; Stajich, J.E.; De Vries, R.P.; Record, E.; Levasseur, A.; Baker, S.E.; et al. Genome sequence of the model mushroom Schizophyllum commune. Nat. Biotechnol. 2010, 28, 957-963. [CrossRef] 
19. Sullivan, R.; Smith, J.E.; Rowan, N.J. Medicinal Mushrooms and Cancer Therapy: Translating a traditional practice into Western medicine. Perspect. Biol. Med. 2006, 49, 159-170. [CrossRef]

20. Du, B.; Yang, Y.; Bian, Z.; Xu, B. Characterization and Anti-Inflammatory Potential of an Exopolysaccharide from Submerged Mycelial Culture of Schizophyllum commune. Front. Pharmacol. 2017, 8, 1-11. [CrossRef]

21. Hermann, J. Fungi on Trees: Saprophytes and Parasites That Grow on Wood; Patzer: Blunder, Germany, 2005.

22. Ren, L.; Hemar, Y.; Perera, C.O.; Lewis, G.D.; Krissansen, G.W.; Buchanan, P.K. Antibacterial and antioxidant activities of aqueous extracts of eight edible mushrooms. Bioact. Carbohydr. Diet. Fibre. 2014, 3, 41-51. [CrossRef]

23. Ellman, G.L.; Courtney, K.; Andres, V.; Featherstone, R.M. A new and rapid colorimetric determination of acetylcholinesterase activity. Biochem. Pharmacol. 1961, 7, 88-95. [CrossRef]

24. Espín, J.C.; Soler-Rivas, C.; Wichers, H.J. Characterization of the Total Free Radical Scavenger Capacity of Vegetable Oils and Oil Fractions Using 2,2-Diphenyl-1-picrylhydrazyl Radical. J. Agric. Food Chem. 2000, 48, 648-656. [CrossRef] [PubMed]

25. Arnao, M.B.; Cano, A.; Acosta, M. The hydrophilic and lipophilic contribution to total antioxidant activity. Food Chem. 2001, 73, 239-244. [CrossRef]

26. Benzie, I.F.; Strain, J. Ferric reducing/antioxidant power assay: Direct measure of total antioxidant activity of biological fluids and modified version for simultaneous measurement of total antioxidant power and ascorbic acid concentration. Link. Biomacromol. 1999, 299, 15-27. [CrossRef]

27. Nishikimi, M.; Rao, N.A.; Yagi, K. The occurrence of superoxide anion in the reaction of reduced phenazine methosulfate and molecular oxygen. Biochem. Biophys. Res. Commun. 1972, 46, 849-854. [CrossRef]

28. Halliwell, B.; Gutteridge, J.M.; Aruoma, O.I. The deoxyribose method: A simple "test-tube" assay for determination of rate constants for reactions of hydroxyl radicals. Anal. Biochem. 1987, 165, 215-219. [CrossRef]

29. Green, L.; Wagner, D.A.; Glogowski, J.; Skipper, P.L.; Wishnok, J.S.; Tannenbaum, S.R. Analysis of nitrate, nitrite, and [15N]nitrate in biological fluids. Anal. Biochem. 1982, 126, 131-138. [CrossRef]

30. Limbago, B. M100-S11, Performance standards for antimicrobial susceptibility testing. Clin. Microbiol. Newsl. 2001, 23, 49. [CrossRef]

31. Weinstein, M.P.; Limbago, B.; Patel, J.B.; Mathers, A.J.; Burnham, C.; Mazzulli, T.; Campeau, S.; Munro, S.D.; Conville, P.S.; Doer, C.; et al. Methods for Dilution Antimicrobial Susceptibility Tests for Bacteria That Grow Aerobically, 9th ed.; Clinical and Laboratory Standards Institute: Wayne, PA, USA, 2012; Volume 32.

32. Karaman, M.; Kaisarevic, S.; Somborski, J.; Kebert, M.; Matavulj, M. Biological activities of the lignicolous fungus Meripilus giganteus (Pers.: Pers.) Karst. Arch. Biol. Sci. 2009, 61, 853-861. [CrossRef]

33. Singleton, V.L.; Orthofer, R.; Lamuela-Raventós, R.M.; Lester, P. Analysis of total phenols and other oxidation substrates and antioxidants by means of Folin-Ciocalteu reagent. Methods Enzymol. 1999, 299, 152-178.

34. Chaplin, M.F.; Kennedy, J.F. Carbohydrate Analysis: A Practical Approach, 2nd ed.; IRL Press: Oxford, UK, 1986 ; pp. 1-36.

35. Orčić, D.; Francišković, M.; Bekvalac, K.; Svirčev, E.; Beara, I.; Lesjak, M.; Mimica-Dukic, N. Quantitative determination of plant phenolics in Urticadioica extracts by high-performance liquid chromatography coupled with tandem mass spectrometric detection. Food Chem. 2014, 143, 48-53. [CrossRef] [PubMed]

36. Mousaviasl, S.; Saleh, T.; Shojaosadati, S.A.; Boddohi, S. Synthesis and characterization of schizophyllan nanogels via inverse emulsion using biobased materials. Int. J. Biol. Macromol. 2018, 120, 468-474. [CrossRef] [PubMed]

37. Yan, J.; Wu, L.-X.; Qiao, Z.-R.; Cai, W.-D.; Ma, H. Effect of different drying methods on the product quality and bioactive polysaccharides of bitter gourd (Momordica charantia L.) slices. Food Chem. 2019, 271, 588-596. [CrossRef] [PubMed]

38. Kozarski, M.; Klaus, A.; Niksic, M.; Vrvić, M.M.; Todorovic, N.; JakovljeviĆ, D.; Van Griensven, L.J. Antioxidative activities and chemical characterization of polysaccharide extracts from the widely used mushrooms Ganoderma applanatum, Ganoderma lucidum, Lentinusedodes and Trametes versicolor. J. Food Compos. Anal. 2012, 26, 144-153. [CrossRef]

39. Šandula, J.; Kogan, G.; Kačuráková, M.; Machová, E. Microbial $(1 \rightarrow 3)-\beta$-d-glucans, their preparation, physico-chemical characterization and immunomodulatory activity. Carbohydr. Polym. 1999, 38, 247-253. [CrossRef]

40. Chen, Z.; Yin, C.; Fan, X.; Ma, K.; Yao, F.; Zhou, R.; Shi, D.; Cheng, W.; Gao, H. Characterization of physicochemical and biological properties of Schizophyllum commune polysaccharide extracted with different methods. Int. J. Biol. Macromol. 2020, 156, 1425-1434. [CrossRef]

41. Mathlouthi, M.; Koenig, J.L. Vibrational Spectra of Carbohydrates. Adv. Carbohydr. Chem. Biochem. 1987, 44, 7-89. [CrossRef]

42. Jamshidian, H.; Shojaosadati, S.A.; Vilaplana, F.; Mousavi, S.M.; Soudi, M.R. Characterization and optimization of schizophyllan production from date syrup. Int. J. Biol. Macromol. 2016, 92, 484-493. [CrossRef]

43. Orhan, I.E.; Kartal, M.; Tosun, F.; Şener, B. Screening of Various Phenolic Acids and Flavonoid Derivatives for their Anticholinesterase Potential. Z. Nat. C 2007, 62, 829-832. [CrossRef]

44. Szwajgier, D. Anticholinesterase Activity of Phenolic Acids and their Derivatives. Z. Nat. C 2013, 68, 125-132. [CrossRef]

45. Tešanović, K.; Pejin, B.; Šibul, F.; Matavulj, M.; Rašeta, M.; Janjušević, L.; Karaman, M. A comparative overview of antioxidative properties and phenolic profiles of different fungal origins: Fruiting bodies and submerged cultures of Coprinus comatus and Coprinellus truncorum. J. Food Sci. Technol. 2017, 54, 430-438. [CrossRef] [PubMed]

46. Ali, Y.; Jannat, S.; Jung, H.A.; Choi, R.J.; Roy, A.; Choi, J.S. Anti-Alzheimer's disease potential of coumarins from Angelica decursiva and Artemisia capillaris and structure-activity analysis. Asian Pac. J. Trop. Med. 2016, 9, 103-111. [CrossRef] [PubMed] 
47. Zhang, Y.; Yang, X.; Jin, G.; Yang, X.; Zhang, Y. Polysaccharides from Pleurotus ostreatus alleviate cognitive impairment in a rat model of Alzheimer's disease. Int. J. Biol. Macromol. 2016, 92, 935-941. [CrossRef] [PubMed]

48. Abdullah, N.; Ismail, S.M.; Aminudin, N.; Shuib, A.S.; Lau, B.F. Evaluation of Selected Culinary-Medicinal Mushrooms for Antioxidant and ACE Inhibitory Activities. Evid. Based Complement. Altern. Med. 2012, 2012, 1-12. [CrossRef] [PubMed]

49. Karaman, M.; Tešanović, K.; Novaković, A.; Šibul, F.; Živić, M.; Stevanović, K.; Pejin, B. Fatty Acids Predominantly Affect Anti-Hydroxyl Radical Activity and FRAP Value: The Case Study of Two Edible Mushrooms. Antioxidants 2019, 8, 480. [CrossRef]

50. Chandrawanshi, N.K.; Tandia, D.K.; Jadhav, S.K. Nutraceutical Properties Evaluation of Schizophyllum commune. Indian J. Sci. Res. 2017, 13, 57-62.

51. Tripathi, A.M.; Tiwary, B.N. Biochemical constituents of a wild strain of Schizophyllum commune isolated from AchanakmarAmarkantak Biosphere Reserve (ABR), India. World J. Microbiol. Biotechnol. 2013, 29, 1431-1442. [CrossRef]

52. Emsen, B.; Kaya, A.K.A.; Cinar, S.; Aasim, M.; Sadi, G. In vitro cytotoxicity, antibacterial and antioxidant properties of various extracts from Schizophyllum commune Fr. Fresenius Environ. Bull. 2017, 26, 1144-1153.

53. Razak, D.L.A.; Fadzil, N.H.M.; Jamaluddin, A.; Rashid, N.Y.A.; Sani, N.A.; Manan, M.A. Effects of different extracting conditions on anti-tyrosinase and antioxidant activities of Schizophyllum commune fruit bodies. Biocatal. Agric. Biotechnol. 2019, $19,101116$. [CrossRef]

54. Basso, V.; Schiavenin, C.; Mendonça, S.; De Siqueira, F.G.; Salvador, M.; Camassola, M. Chemical features and antioxidant profile by Schizophyllum commune produced on different agroindustrial wastes and byproducts of biodiesel production. Food Chem. 2020, 329, 127089. [CrossRef] [PubMed]

55. Jiamworanunkul, S. Effective antioxidant production through submerged fermentation of edible mushrooms. Thai J. Pharm. Sci. 2019, 43, 213-218.

56. Mayakrishnan, V.; Abdullah, N.; Abidin, M.H.Z.; Fadzil, N.H.M.; Johari, N.M.K.; Aminudin, N.; Abidin, N.Z. Investigation of the Antioxidative Potential of Various Solvent Fractions from Fruiting Bodies of Schizophyllum commune (Fr.) Mushrooms and Characterization of Phytoconstituents. J. Agric. Sci. 2013, 5, 1-11. [CrossRef]

57. Velderrain-Rodríguez, G.R.; Torres-Moreno, H.; Villegas-Ochoa, M.A.; Ayala-Zavala, J.F.; Robles-Zepeda, R.E.; Wall-Medrano, A.; González-Aguilar, G.A. Gallic Acid Content and an Antioxidant Mechanism Are Responsible for the Antiproliferative Activity of 'Ataulfo' Mango Peel on LS180 Cells. Molecules 2018, 23, 695. [CrossRef]

58. Rice-Evans, C.; Miller, N.; Paganga, G. Antioxidant properties of phenolic compounds. Trends Plant Sci. 1997, 2, 152-159. [CrossRef]

59. Kozarski, M.; Klaus, A.; Jakovljevic, D.; Todorovic, N.; Vunduk, J.; Petrovic, P.; Niksic, M.; Vrvic, M.; Van Griensven, L.J. Antioxidants of Edible Mushrooms. Molecules 2015, 20, 19489-19525. [CrossRef]

60. Duncan, S.H.; Leitch, E.C.M.; Stanley, K.N.; Richardson, A.J.; Laven, R.; Flint, H.J.; Stewart, C.S. Effects of esculin and esculetin on the survival of Escherichia coli $\mathrm{O} 157$ in human faecal slurries, continuous-flow simulations of the rumen and colon and in calves. Br. J. Nutr. 2004, 91, 749-755. [CrossRef]

61. Alves, M.J.; Ferreira, I.C.F.R.; Froufe, H.J.C.; Abreu, R.M.V.; Martins, A.; Pintado, M. Antimicrobial activity of phenolic compounds identified in wild mushrooms, SAR analysis and docking studies. J. Appl. Microbiol. 2013, 115, 346-357. [CrossRef]

62. Díaz-Gómez, R.; Toledo-Araya, H.; López-Solís, R.; Obreque-Slier, E. Combined effect of gallic acid and catechin against Escherichia coli. LWTFood Sci. Technol. 2014, 59, 896-900. [CrossRef]

63. Arun, G.; Eyini, M.; Gunasekaran, P. Characterization and biological activities of extracellular melanin produced by Schizophyllum commune (Fries). Indian J. Exp. Biol. 2015, 53, 380-387. 